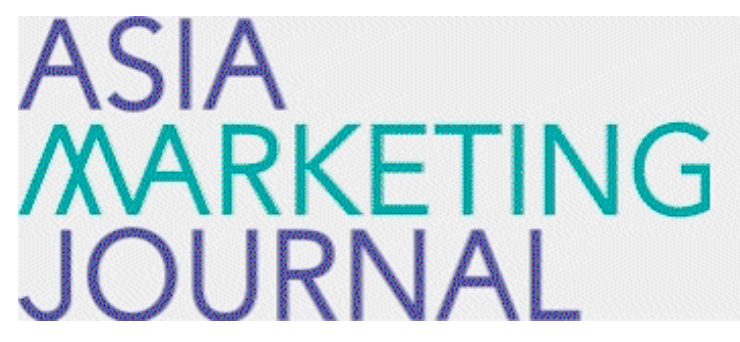

ASIA MARKETING JOURNAL

Volume 14 | Issue 3

Article 6

10-30-2012

\title{
Music as a Magical Cue
}

In Suk Hwang

Eugene J S Won

Sook Eun Byun

Follow this and additional works at: https://amj.kma.re.kr/journal

Part of the Marketing Commons

\section{Recommended Citation}

Hwang, In Suk; Won, Eugene J S; and Byun, Sook Eun (2012) "Music as a Magical Cue," Asia Marketing Journal: Vol. 14 : Iss. 3 , Article 6.

Available at: https://doi.org/10.53728/2765-6500.1491

This Article is brought to you for free and open access by Asia Marketing Journal. It has been accepted for inclusion in Asia Marketing Journal by an authorized editor of Asia Marketing Journal. 


\title{
Music as a Magical Cue: \\ An Exploratory Study of Background Music and Purchase Intentions in TV Home Shopping Programs
}

\author{
Insuk Hwang* \\ Eugene J. S. Won** \\ Sookeun Byun***
}

Although music is one of the most important attributes of broadcasting communications, few studies have examined the relationship between background music and the behavior of audiences, particularly in the context of TV home shopping programs, where purchase decisions are made while watching the show.

The objective of this study is to examine whether certain characteristics of music in broadcasting communications can affect the audiences purchase intentions or behaviors. Unlike previous studies on this issue, this study considers the impulse-inducing capability (IIC) of music as an important variable affecting consumers purchase intension.

A 2x3 (high/low involvement and high/low/no IIC music) between subjects design was used for the experiments in the study. The TV home shopping programs in the high or low involvement condition were identical except for the type of background music: high IIC music, low IIC music, and no music. A total of 188 undergraduate students at a college in Seoul, South Korea participated in the study. Their ages range from 20 to 25 (median age $=22$ ), and nearly $60 \%$ were male.

Our analysis showed that in the low involvement condition, high IIC music was more likely to have a positive effect on purchase intentions than low IIC (common) music or no music did. Meanwhile, there was not any significant relationship between music and purchase intentions in the high involvement condition. Given that previous studies have provided no clear evidence of the effects of music on consumers purchase intentions or behaviors, this study makes an important contribution to the literature in this field. The result of this study provides implications to the practitioners in the market, too. Marketers need to reevaluate the value of music used in broadcasting communications and pay more attention to find the right music for their campaigns. Limitations of this study as well as directions for future studies are also discussed.

Key words: Background Music, TV Home Shopping Programs, Impulse-Inducing Capability (IIC) of Music

* Professor of Marketing. Department of Business Administration. University of Seoul(hwangis@uos.ac.kr), Corresponding Author

** Associate Professor of Marketing. Department of Business Administration. Dongduk Women's University (eugene1@dongduk.ac.kr)

*** Assistant Professor of Marketing. Department of Business Administration. Kwangwoon University(sebyun@kw.ac.kr) 


\section{Introduction}

Many studies have examined the effects of various features of broadcasting communications, such as background music and color, on the audiences purchase intentions and behaviors. For example, Gorn's (1982) seminal work on the effects of music on consumer choice showed that consumers' product preferences are directly influenced by their simultaneous exposure to a given product and music in the advertisement. However, his findings have sparked a controversy because other researchers have had difficulty in identifying significant effects of background music on consumers' purchase intentions or behaviors. Allen and Madden (1985), Pitt and Abratt (1988), and Kellaris and Cox (1989) replicated the Gorn's experiment, but found no significant effects of music on the audiences' choice behavior. The present study poses that these findings may be due to unique characteristics of ordinary TV or radio advertisements. If so, an experiment in the context of TV home shopping may produce different results.

TV home shopping shows have characteristics that are different from those of ordinary TV or radio advertising (Hwang \& Won, 2006). First, a TV home shopping show airs longer than ordinary TV or radio advertising. The reason that previous studies have failed to show any significant effect of background music in TV or radio advertisements on consumption behavior may be due to the relatively short exposure time to the ads. In a similar vein, music has been shown to influence consumers' purchase intentions or behaviors in retail environments such as restaurants and supermarkets, where background music is generally played for a long period of time (e.g., Baker, Grewal \& Voss, 2002: Beverland, Lim, Morrison \& Terziovski, 2006: Caldwell \& Hibbert, 2002: Milliman, 1982: Morin, Dube \& Chebat, 2007). In this regard, TV home shopping, because of its relatively long air time, seems to be a good environment for examining the effects of background music on consumption behavior.

Another distinct characteristic of TV home shopping shows is that consumers should make purchasing decisions while they are being exposed to those. In contrast, there is a distinct temporal gap between the exposure to ordinary TV advertisement and the actual purchase of the product in the market. Considering that brand preferences formed through peripheral cues such as background music generally do not last long (Petty \& Caccioppo, 1985), such temporal gap would diminish the effect of background music on purchase behavior. Nevertheless, previous studies on consumer responses to background music in TV advertisements measured purchases intentions even after performing some distractive tasks, as well as exposing to the advertisement.

Given the above discussion, TV home shopping seems to be an optimal condition for observing 
the audiences' responses to background music. So, the present study investigates the effects of background music features in TV home shopping programs on consumers' purchase intentions. In this unique context, this study employs two unconditioned stimuli, namely two types of background music with different levels of impulse-inducing capability (IIC). The result of this study is expected to provide important theoretical and practical implications for the literature in this field.

\section{Background and Hypotheses}

\subsection{The Effects of Music on Consumer Behaviors in TV or Radio Advertising}

Allan (2008) found that $94 \%$ of 3,456 primetime TV commercials contained some type of music. Advertisers make extensive use of background music because it is considered as an important strategic tool for maximizing the effectiveness of advertising. For example, Bruner (1990) suggested that music can foster moods or emotions suitable for advertising. However, previous studies produced mixed results for the role of background music in consumers' message recall. For instance, Anand and Sternthal (1990) found that music has a distracting effect in the context of radio advertising. A number of studies have reported similar findings, including those of Gorn, Goldberg. Chattopadhyay, and Litvack (1991), Sewall and Sarel (1986), and Stout and Leckenby (1988). By contrast, some studies such as Hoyer, Srivastava, and Jacoby (1984) and Wallace (1991) supported the idea that music enhances communication effectiveness.

To resolve the controversy, researchers have examined whether certain characteristics of music can explain such mixed results. Kellaris, Cox, and Cox (1993) examined this issue by manipulating the types of music in terms of the music-message congruency and the attentiongaining value and found that the attentiongaining value of music can moderate the effects of the music-message congruency on advertising recall and recognition. However, they acknowledged their use of purely instrumental and generally unfamiliar music as the stimulus.

Roehm (2001) examined whether the effects of vocal music are different from those of instrumental music in the context of advertising. They found that when audiences were familiar with the song, they recalled the message implied by the lyrics for an instrumental version of the song more easily than for a vocal version. In contrast, when the audiences were not familiar with a song, they were more likely to recall the message for a vocal version than for an instrumental version. Similarly, Allan (2006) indicated that vocal music is a more effective stimulus for brand name recall than instrumental music.

As discussed above, many researchers have attempted to better explain the effects of back- 
ground music in advertising by focusing on the type of music used to the advertising. Meanwhile. a number of previous studies have a limitation in that they measured the effects of background music on consumers' cognitive or emotional responses rather than behavioral responses.

\subsection{The Effects of Music on Consumer Behaviors in the Retail Environment}

Although most previous studies were unable to verify the effects of music on purchase behaviors in TV or radio advertising. some did provide evidence of its effects on the in-store shopping behaviors. For example, Baker, Grewal, and Voss (2002) and Caldwell and Hibbert (2002) found that music preferences have significant effects on patronage intentions and the amount of money spent in restaurants or supermarkets.

Several studies investigated whether the characteristics of music can explain the inconsistent findings in retail settings. Caldwell and Hibbert (2002) found that participants in the fast-tempo music group spent significantly more money on restaurants than those in the slowtempo music group, whereas Milliman (1986) found the opposite results. The reason behind these mixed results remains unidentified. Recently, Eroglu, Machleit, and Chebvat (2005) investigated the effects of the tempo of music and found that a fast tempo is more likely than a slow one to influence behavioral responses such as approach and avoidance tendencies and the extent of browsing behavior in in-store shopping contexts. Herrington (1996) found that musical preferences are more likely to influence the amount of time or money that shoppers spend on various services than the tempo or volume of music. These studies generally imply that certain characteristics of music can explain the equivocal findings of previous research on the effects of background music in broadcasting communications.

\subsection{The Impulse-Inducing Capability(IIC) of Music}

Yalch and Spangenberg (2000) compared the effects of popular hit songs and instrumental easy-to-listen music in a department store. Their study showed that younger shoppers under the age of twenty-five perceived their shopping time longer under the easy-to-listen music condition, whereas older shoppers perceived their shopping time longer under the hit songs music condition. Bruner (1990) reviewed the past literature extensively and concluded that music used in marketing-related contexts is capable of evoking behavioral responses in consumers. Considering the TV home shopping show is one of marketingrelated contexts, we expect that music used in the show also influences viewers' behavioral responses. Specifically this study proposes that music with high impulse-inducing capability (IIC) in a TV home shopping show can influence consumers' purchase behavior. We defines the 
impulse-inducing capability (IIC) of music as the extent to which music induces individuals to act spontaneously, unreflectively, and immediately

An impulse or impulsiveness is a basic human trait and refers to the tendency to act spontaneously, unreflectively, and immediately (Dickman. 1990: Gerbing. Ahadi \& Patton, 1987: Rook $\&$ Fisher, 1995). Previous studies have suggested that consumers with a strong impulsive tendency are more likely to experience spontaneous buying stimuli and be receptive to sudden and unexpected buying ideas (Rook \& Fisher, 1995). Therefore, consumers with a high impulsive tendency are more likely to show impulsive buying behaviors than those with a low impulsive tendency. The present study suggests that music may induce consumers impulsive tendency. Dunbar (1990) found that music has a magical communication dimension that can induce consumers' involuntary sensual or behavioral responses. Feeling a shudder, getting goose bumps, having one's hair stand on end, and yelling loudly while listening to music can represent spontaneous, unreflective, and immediate responses. This suggests that the IIC of music may have considerable influence on consumers' purchase intentions in the context of broadcasting communications. The prediction is in accordance with the study of Clynes (1982) and Bruner (1990) indicating that music acts on the nervous system like a key on a lock and music has an ability to achieve various purposes.

As discussed earlier, in the context of TV home shopping shows, a consumer's purchase decision is made while it is being communicated. This suggests that music may have significant effects on purchasing decisions in the home shopping context and thus that high IIC music may induce consumers' purchase intentions. In summary, this study hypothesizes that high IIC music would be more likely than low IIC (i.e.. common) or no music to have a positive effect on audiences purchase intentions in the context of TV home shopping shows. However, such effects may be valid only for consumers in a low involvement environment. The following section provides a more detailed explanation.

\subsection{The Effects of Music on Consumer Behaviors under Low or High Involvement Conditions}

It is widely known that the level of involvement is determined by the personal significance or relevance that a consumer ascribed to various features of an object such as a message, situation, or product (Te'eni-Harari and LehmanWilzig. 2009). It should be noted that involvement is a matter of interpretation, not the object itself.

Employing the concept of involvement, Petty and Cacioppo (1985) and Petty. Cacioppo, and Schumann (1983) suggested that peripheral cues such as music and photos can have considerable influence on low-involved consumers' responses because these consumers generally engage in 
non-message-based processing. On the other hands, high-involved consumers are known to ignore such cues and focus on spoken or written messages in the advertisement for their rational decision making. That is, music may have significant effects only under a low involvement condition.

Many researchers empirically examined whether peripheral cues such as background music have differential effects on consumers' involvement level. For example, Park and Young (1986)'s study showed that background music in TV advertisement influenced consumers' brand attitudes in the low involvement condition but not in the high involvement condition. However, no significant effect on purchase intentions was found, regardless of the level of involvement, in their study. Nevertheless, it is premature to conclude that the level of involvement has no significant effect on purchase intentions or behaviors because few studies have empirically measured them so far, instead of beliefs about or memory of the message or brand. In an effort to contribute to the literature in this subject, therefore, this study examines whether purchase intentions differ when consumers are in low and high involvement conditions respectively. In this regard, we propose the following hypotheses:

H1: High IIC music is more likely to induce low involvement consumers' purchase intentions toward the products communi- cated through TV home shopping shows than low IIC music.

H2: High IIC music is more likely to induce low involvement consumers' purchase intentions toward the products communicated through TV home shopping shows than no music.

\section{Method}

\subsection{Stimuli and the Experimental Design}

To manipulate the level of involvement (low vs. high) for purchase situations, two different TV home shopping programs were produced with the help of an advertising agency: one for the low involvement condition and the other for the high involvement condition. These two shows featured different products. The show for the low involvement condition advertised a seafood snack. In some countries in Asia, seafood snacks are popular across all ages, and they are consumed mainly to kill time (e.g., eating snacks while watching a baseball game or a movie). This study's seafood snack product was being sold in a bundle of 20 packages at $\$ 18$. The show for the high involvement condition advertised a desktop computer with a price of $\$ 800$.

For each involvement condition, we employed 
three different versions of the show (one with high IIC music, one with low IIC music (i.e., common music), and one with no music). The three shows for each involvement condition were identical except for the type of background music (high IIC music, low IIC music, and no music). Namely, we used a total of six shows for the experiment.

We played high or low IIC music throughout the presentation of each show, which lasted eight minutes (the average air time in the U.S.). We used a popular song that was approximately four minutes in length and the song repeated twice during each show. We displayed the core message in the bottom left corner of TV screen throughout the presentation. The messages for the low involvement condition included information on price, lead time, taste, and other product attributes. Those for the high involvement condition included information on price, lead time. capacity of hard disk memory/RAM, and other product attributes. In addition, at the beginning and end of each show, the show host verbalized these messages. While the show host delivered a message, the volume of background music was adjusted slightly lower so the audience can hear the message clearly.

A total of 188 undergraduate students at a Korean college participated in the study. Their ages ranged from 20 to 25 (median age $=22$ ), and nearly $60 \%$ were male. After the experiment, we provided them with some reward for their participation. We randomly assigned and exposed each participant to one of the six versions of the shows.

\subsection{Pretest}

A pretest was conducted in order to select music samples with high IIC and low IIC for main experiment. First, the researchers of this study selected 18 music samples that are considered as popular among consumers. The rationale behind selecting popular songs was to reflect the real world, in which marketer generally use popular songs for background music. The selected 18 music samples were presented to thirty-four undergraduate students, who were different from the ones in the main experiment. During this procedure, we allowed them to watch the experimental show on the TV screen. Each participant rated the music samples in terms of IIC level (see the Measurement section) after listening to each sample for one minute in a laboratory.

Along with the level of IIC, we asked the participants to rate the degree of fit between each music sample and the concept of each show on a seven-point scale. Previous studies (e.g., Kellaris, Cox \& Cox, 1993: Macinnis \& Park, 1991) have considered the fit between music and advertising as an important variable that influences the effectiveness of advertising.

Based on the pretest results, we selected "Every Breath You Take" (the Police) as high IIC music (average IIC level $=5.01$ ) and "You 
Needed Me" (Anne Murray) as low IIC music (average IIC level $=2.85$ ). There was a significant difference in the IIC level between these two songs at the $\mathrm{p}=.001$ level $(t=5.90$. $d f=33$.

In the case of the seafood snack, the degree of fit between background music and the show concept for high IIC music was 3.44, and that for low IIC music was 3.11. There were no significant mean differences $(t=1.40, d f=$ 33. n.s.). In the case of the computer show, the degree of fit for high IIC music was 3.58 , and that for low IIC music was 3.32. Again, there were no significant mean differences $(t=.63$, $d f=33$, n.s. $).$

\subsection{Procedure}

The experiment took place during regular undergraduate classes. Before the experiment, we explained that the purpose of the study is to analyze consumers' responses to TV home shopping shows: they would watch several eight-minute shows: and their responses to the shows and the products would be measured. Each participant watched three shows: experimental show and two professionally made filler shows (a \$200 tent and a \$100 bicycle). Before the participants watched a series of the shows, we asked several questions about their general views on TV home shopping.

We asked the participants in the high involvement condition to assume that they were really planning to purchase the communicated product and had to recommend it to a close friend, whereas we did not impose such assumption on those in the low involvement condition (the seafood snack). In order to control primacy and recency effects, we positioned the target show between the two filler shows in both the low and high involvement conditions.

Because actual purchases in TV home shopping are made while products are being communicated, we asked the participants to rate their purchase intentions toward the target product during the show presentation. We employed the same procedure for the filler shows. At the end of the procedure, we provided all participants with a debriefing questionnaire and asked them to indicate (in an open-ended format) what they believed to be the purpose of the study and write down any thoughts they had during the experiment.

\subsection{Measurement}

\subsubsection{Measures for the Dependent Variable and the Manipulation Check}

We measured purchase intentions by using three-item, seven-point Likert scale $(a=.88)$ ranging from "improbable" (1) to "probable" (7), from "unlikely" (1) to "likely" (7) and from "definitely would not" (1) to "definitely would" (7). We adapted the items from the studies of Goldsmith and Lafferty (2000) and 
Till and Busler (2000). For further analyses. we took the average values of all multi-item scales.

After watching each show and answering to the questions on purchase intentions, the participants, under the direction of the supervisor, completed items for manipulation check. The participants first evaluated the IIC of music by using three items of a seven-point Liker-type scale. We developed the items for IIC level based on the concept of induced impulses in previous research as well as the concept of the IIC of music defined in the present study. Although one's own impulse may not be perceived by herself, we assume that its consequences such as involuntary sensual or behavioral responses could be perceived (e.g.. "I touched the brand in spite of myself"). Therefore, we measure the IIC of music in an alternative manner. Specifically, the following items were used: "This music is likely to make people dance with their shoulders in spite of themselves". "This music is likely to make people lose their restraint". "This music is likely to make people follow the beat with their hands or feet in spite of themselves" $(a=.72)$. These were based on a seven-point Likert scale ranging from "strongly disagree" (1) to "strongly agree" (7). The participants in the no-music condition did not rate this item.

We measured the level of involvement for a manipulation check. For this, we employed three items adopted from Park and Young
(1986) and Zaichkowsky (1985). These items included "The purchase of the product (the computer or the seafood snack) is important to me," "I watched the show for the product (the computer or the seafood snack) carefully," and "I am very interested in purchasing the product (the computer or the seafood snack)." We measured each item on a seven-point Likert scale ranging from "strongly disagree" (1) to "strongly agree" (7). The items showed a high level of reliability $(a=.90)$.

\subsubsection{Other}

We measured the degree of fit between music with show by using one item. We asked the participants to indicate the extent to which the background music was relevant to or appropriate for the show on a seven-point Likert scale ranging from "not at all" (1) to "very" (7). The participants watched the show again for 30 seconds for this item because some might not have clearly remembered the background music.

\section{Results}

\subsection{Manipulation Check and Demand Effects}

We conducted manipulation checks for the 
items measuring IIC of music and the level of involvement. The participants in the high IIC condition rated the IIC level higher $(M=$ 4.51) than those in the low IIC condition $(M=$ 2.99). There was a significant mean difference in the IIC level $\left(F_{(1.126)}=35.47, p<.001\right)$. In terms of the level of involvement, the means were 3.68 and 6.01 for the low and high involvement conditions respectively, and this difference was significant $\left(F_{(1.126)}=182.79, p<\right.$ .001 ). These results indicate the successful manipulation of the IIC of music and the level of involvement.

For the seafood snack, the degree of fit between the show and its music for high IIC music was 3.32 , whereas that for low IIC music was 3.01. For the computer, the degree of fit for high IIC music was 3.53 , whereas that for low IIC music was 3.31. These differences were not statistically significant $\left(F_{(1.61)}=2.20\right.$ and $F_{(1.63)}$ $=2.11$, respectively, n.s.). The lack of significance excludes any possible effects of fit of music as an exogenous variable on this study's results.

We checked for any demand effects by examining the participants' responses to openended questions at the end of the procedure. A few respondents were found to have guessed the research purpose right. So we excluded their answers from the analyses.

\subsection{Comparison of Effects of High IIC and Low IIC Music on Purchase Intentions in Each Involvement Condition}

We analyzed the mean difference among the groups with different types of music for each involvement condition. There was a significant difference among the groups in the low involvement condition $\left(F_{(2.90)}=3.46, p<.05\right.$. Table 1) but not in the high involvement condition $\left(F_{(2.92)}=.15\right.$, n.s., Table 1). So, we compared the scores for purchase intentions between the group exposed to high IIC music and that exposed to low IIC (common) music under the low involvement condition. The group comparison test showed a significant mean difference in the scores. The mean score for the high IIC group was 4.09 , whereas that for the low IIC group was $3.27\left(F_{(1.61)}=3.56, p<.05\right.$. Table 1). In addition, there was a significant difference between the high IIC group and the no-music group, whose mean scores were 4.09 and 3.33 . respectively $\left(F_{(1.59)}=3.32, p<.05\right.$, Table 1$)$. Such result indicated that background music in broadcasting communications can influence consumers' purchase intentions or behaviors, which was not clearly shown in previous studies.

We also compared the scores for purchase intentions between the groups under the high involvement condition. The mean score for the high IIC group was 3.28 , whereas that for the low IIC group was 3.11. This difference was 
〈Table 1) Means for Purchase Intentions for Each Experimental Group

\begin{tabular}{|c|c|c|c|c|}
\hline & $\begin{array}{c}\text { High IIC } \\
\text { Music }\end{array}$ & $\begin{array}{c}\text { Low-IIC } \\
\text { Music }\end{array}$ & $\begin{array}{c}\text { No } \\
\text { Music }\end{array}$ & F-Value \\
\hline Low-Involvement & 4.09 & 3.27 & 3.33 & $3.46^{*}$ \\
Condition & $(1.41)$ & $(1.43)$ & $(1.53)$ & \\
\hline High Involvement & 3.28 & 3.11 & 3.30 & .15 \\
Condition & $(1.47)$ & $(1.49)$ & $(1.35)$ & \\
\hline
\end{tabular}

Values in parentheses indicate standard deviations: ${ }^{*} p<.05$.

not significant $\left(F_{(1.63)}=.15\right.$, n.s., Table 1$)$. In addition, there was no difference between the high IIC group and the no-music group (3.28 vs. 3.30, $F_{(1,60)}=.01$, n.s., Table 1). These results are in line with our prediction, suggesting that in high involvement purchase contexts. background music has no significant effect on consumers purchase intentions, even in the case of TV home shopping.

\section{Discussion}

\subsection{Music Can Be a Magical Cue for Products under the Low Involvement Condition}

The general objective of this study is to examine whether certain characteristics of music in broadcasting communications can explain previous studies' mixed results for the audiences' purchase intentions or behaviors. Unlike previous research, this study considered the IIC of music, hypothesizing that music can influence consumers purchase behavior if it has high level of IIC. An experiment was conducted under TV home shopping environment where its air time is relatively longer and consumers should make purchasing decisions while they are being exposed to the program. The results of our experiment showed a significant relationship between the IIC of music and the participants' purchase intentions. More specifically, in the low involvement condition, high IIC music was more likely to have a positive effect on purchase intentions than low IIC (common) music or no music did. Given that previous studies have provided no clear evidence of the effects of music on consumers purchase intentions or behaviors, such finding makes an important contribution to the literature in this arena. Although this study's results are only from TV home shopping shows, they have important implications for the venue because TV home shopping and regular TV advertising share the common purpose of inducing consumers to buy products shown on the TV screen.

Music has not been considered as important so far as other attributes of broadcasting com- 
munications, including copy, endorsers, and visual factors (Hung, 2001). In many cases, music is not chosen based on the marketing strategy, which suggests that it is generally viewed as a nonessential factor in communication (McQuarrie \& Mick, 1992). However, this study's results demonstrate the huge potential of music to motivate consumers purchase intentions. Several studies identified music as a major peripheral cue that consumers use when making purchasing decisions when they are low-involved (Gorn, 1982: Hung, 2001: Milliman, 1986). The result of this study can be understood in the same vein: consumers use background music in advertising as an important cue for purchase decision making in low involvement context. It implicates that practitioners in the market, including home shopping marketers, need to reevaluate the value of music used in broadcasting communications and pay more attention to find the right music for their campaigns.

\subsection{Then How Can Products Be Promoted under the High Involvement Condition?}

Unlike the case of the low involvement condition, there was no significant relationship between music and purchase intentions in the high involvement condition. This raises the question of whether music is an inconsequential factor in TV home shopping shows for products in high involvement contexts. By contrast, this may imply that home shopping marketers should employ a distinct communication strategy for products in high involvement contexts. Media reports and studies have indicated that the best-selling products in home shopping are the so-called low involvement products such as CDs, books, and some household products. As for high involvement products, prices and differences in consumers' consuming information can be discussed (Petty, Cacioppo \& Schumann, 1983: Petty \& Cacioppo, 1985). In general, individuals need some time for research before making a decision to buy high involvement products such as cars and real estate properties. Therefore, such products have been considered as less desirable for home shopping programs (Park \& Young. 1986).

In contrast, some researchers have proposed that special strategies can be used to induce consumers to perceive a high involvement product as a low involvement one, thus making them act in accordance with their usual behavior for low involvement products (Hung, 2001). For example, marketers may encourage the use of a trial version of the product or rent it for a certain period of time to minimize consumers' perceived risk or psychological pressure. These strategies exist, for example, among some automobile companies. In this case, some may perceive that the role of home shopping programs is somewhat limited because they only gather consumers for the product trial. However, such foot-in-the door communication techniques are 
frequently used by marketers to persuade consumers in some contexts. In such cases, background music may play a crucial role in consumers purchase decisions because they are expected to be less involved in the purchasing decision, although the shopping host is promoting a type of high involvement product.

\subsection{Limitations and Suggestions}

This study has some limitations. First, we tested the hypotheses in a restricted manner because two different products, namely a seafood snack and a desktop computer, were used for the low and high involvement conditions respectively. In this regard, this study's results should be interpreted with caution. Second, this study employed young consumers only for the experiment. It is true that young consumers represent a major consumer group in our society, but this group is more likely to be influenced by communication elements such as music than other consumer groups. In this regard, future research should consider other consumer groups with different demographic backgrounds. In addition, although we selected the music samples through a pilot study, future research need to consider a wider range of music genres (e.g., rock, pop, jazz, contemporary, and new age) as well as styles (e.g., with/ without lyrics and a slow or fast tempo) to verify the result. Such efforts would provide a better understanding of the IIC of music. Lastly, we recommend future research to examine the differential effects of the IIC of music on other types of broadcasting communications, such as radio, to provide more meaningful implications for communication practitioners.

〈Recieved June 2. 2012〉 〈1st Revised August 7. 2012〉 〈2nd Revised October 15. 2012〉 〈Accepted October 16. 2012〉

\section{References}

Allen, Chris and Thomas J. Madden (1985), "A Closer Look at Classical Conditioning," Journal of Consumer Research, 12(Dec.). 301-315.

Allen, David (2006), "Effects of Popular Music in Advertising on Attention and Memory," Journal of Advertising Research, 46(4). 434-445.

Allan, David. (2008) "A Content Analysis of Music Placement in Prime-Time Television Advertising," Journal of Advertising $\mathrm{Re}^{-}$ search, 48(3), 404-417.

Anand, P. and B. Sternthal (1990), "Ease of Message Processing as a Moderator of $\mathrm{Re}^{-}$ petition Effects in Advertising," Journal of Marketing Research, 27, 345-353.

Baker, J., A. Parasuraman, D. Grewal, and G. B. Voss (2002), “The Influence of Multiple Store Environment Cues on Perceived Mer- 
chandise Value and Patronage Intentions," Journal of Marketing, 66(April), 120-141.

Beverland, M., E. A. C. Lim, M. Morrison, and M. Terziovski (2006), "In-Store Music and Consumer-Brand Relationship: Relational Transformation Following Experiences of (Mis) Fit," Journal of Business Research, 59, 982-989.

Bruner II, G. C. (1990), "Music, Mood, and Marketing," Journal of Marketing. 54(4). 94-103.

Caldwell, C. and S. A. Hibbert (2002), "The Influence of Music Tempo and Musical Preference on Restaurant Patrons' Behavior,"

Psychology and Marketing, 19(11), 895-917. Clynes (1982), "Specific Human Emotions Are

Psychobiologic Entities: Psychobiologic Coherence between Emotion and Its Dynamic Expression," Behavioral and Brain Sciences, 5(Sep.), 424-425.

Dickman, S. J. (1990), "Functional and Dysfunctional Impulsivity: Personality and $\mathrm{Cog}^{-}$ nitive Correlates," Journal of Personality and Social Psychology, 58, 95-102.

Dunbar, David S. (1990), "Music, and Advertising," International Journal of Advertising, 9(3), 197-203.

Eroglu, Sevgin A., Karen A. Machleit, and Jean-Charles Chebat (2005), "The Interaction of Retail Density and Music Tempo: Effects on Shopper Responses," Psychology and Marketing, 22(7), 577-589.

Gerbing, David W., Stephan A. Ahadi, and
Jim H. Patton (1987), "Toward a Conceptualization of Impulsivity: Components across the Behavioral and Self-Report Domains," Multivariate Behavioral Research, 22(July), 357-379.

Goldsmith, Ronald E. and Barbara Lafferty (2000), "The Impact of Corporate Credibility and Celebrity Credibility on Consumer Reaction to Advertisements and Brands," Journal of Advertising, 29(3), 44-54.

Gorn, G. J. (1982), "The Effects of Music in Advertising on Choice Behavior: A Classical Conditioning Approach," Journal of Marketing, 46(1), 94-101.

Gorn, G.J., M. E. Goldberg, A. Chattopadhyay, and D. Litvack, (1991), "Music and Information in Commercials: Their Effects with an Elderly Sample," Journal of Advertising Research, 31(5), 23-32.

Herrington, J. D. (1996), "Effects of Music in Service Environments: A Field Study," Journal of Services Marketing, 10(2), 26-41 Hoyer, W. D., R. K. Srivastava, and J. Jacoby (1984), "Source of Miscomprehension in Television Advertising," Journal of Advertising, 13(2), 17-26.

Hung, K. (2000), "Narrative Music in Congruence and Incongruence TV Advertising," Journal of Advertising, 29(1), 25-34.

Hwang, Insuk and Eugene J. S. Won (2006), "Effects of Background Music on Advertising Effectiveness in TV Home Shopping Show: Roles of Musical Preference and 
Fit with the Product Concept," Korean Marketing Review, 21(3), 47-68.

Kellaris, J. J. and A. D. Cox (1989), "The Effects of Background Music in Advertising:

A Reassessment," Journal of Consumer Research, 16(June), 113-118.

Kellaris, J. J., and R. J. Kent (1991), "Exploring Tempo and Modality Effects on Consumer Responses to Music," Advances in Consumer Research, 18, 243-248.

MacInnis, D. J. and C. W. Park (1991), "The Differential Role of Music on High and Low-involvement Consumers' Processing of Ads," Journal of Consumer Research, 18 (2), 161-173.

McQuarrie, Edward F. and David G. Mick (1992), "On Resonance: A Critical Pluralistic Inquiry into Advertising Rhetoric," Journal of Consumer Research, 19 (2), 180-197.

Milliman, R. E. (1982), “Using Background Music to Affect the Behavior of Supermarket Shoppers." Journal of Marketing. 46(3), 86-91.

Milliman, R. E. (1986), "The Influence of Background Music on the Behavior of Restaurant Patrons," Journal of Consumer Research, 13(2), 286-289.

Morin, S., L. Dube, and J. Chebat (2007), "The Role of Pleasant Music in Servicescapes: A Test of the Dual Model of Environmental Perception," Journal of Retailing, 83(1), 115-130.

Rook, Dennis W. and Robert J. Fisher (1995),
"Normative Influences on Impulsive Buying Behavior," Journal of Consumer Research, 22(Dec.), 305-313.

Park, C. Whan and S. M. Young (1986), "Consumer Response to Television Commercials: The Impact of Involvement and Background Music on Brand Attitude Formation," Journal of Marketing Research, 23(Feb.), 11-24.

Petty. Richard E. and John T. Cacioppo (1985), The Elaboration Likelihood Model of Persuasion, in Advances in Experimental Social Psychology, Vol.19, L. Berkowitz, ed. New York: Academic Press.

Petty, Richard E, John T. Cacioppo, and David Schumann (1983), "Central and Peripheral Routes to Advertising Effectiveness: The Moderating Role of Involvement," Journal of Consumer Research, 10(2), 135-146.

Pitt, Leyland F. and Russell Abratt (1988). "Music in Advertisements for Unmentionable Products- A Classical Conditioning Experiment." International Journal of Advertising, Aug., 130-137.

Roehm, Michelle L. (2001), "Instrumental vs. Vocal Versions of Popular Music in Advertising," Journal of Advertising Research, May/June, 49-58.

Sewall, M. A. and D. Sarel (1986), "Characteristics of Radio Commercials and Their Recall Effectiveness," Journal of Marketing, 50(1), 52-60.

Stout, P. A., and J. D. Leckenby (1988), Let the Music Play: Music as a Nonverbal 
Element in Television Commercials, in $\mathrm{No}^{-}$ nverbal Communication in Advertising, $\mathrm{S}$. Hecker and D. W. Stewart, eds., Lexington, MA: D.C. Heath., 207-223.

Te'eni-Harari, T., Lehman-Wilzig, S., and Lampert, S. I. (2009) "The Importance of Product Involvement for Predicting Advertising Effectiveness among Young People," Journal of Advertising Research, 28(2), 203-229.

Till, B. D. and M. Busler (2000), "The MatchUp Hypotheses: Physical Attractiveness, Expertise, and the Role of Fit on Brand
Attitude, Purchase Intention and Brand Beliefs," Journal of Advertising, 29(3), 1-13. Wallace, W. T. (1991), "Jingles in Advertisements: Can They Improve Recall?" Advances in Consumer Research, 18, 239-242. Yalch, Richard F. and E. Spangenberg (2000), "The Effects of Music in a Retail Setting on Real and Perceived Shopping Times," Journal of Business Research, 49(2), 139148.

Zaichkowsky, Judith L (1985). "Measuring the Involvement Construct," Journal of Advertising Research, 12(3), 341-352. 